\title{
USING A DENTAL OPERATING MICROSCOPE IN THE DIAGNOSTICS OF ASYMPTOMATIC PULPITIS IN PRIMARY TEETH
}

\author{
Maya Rashkova, Natalia Gateva, Nadezhda Mitova, Zornitsa Lazarova, Hristina \\ Tankova. \\ Department of Pediatric Dentistry, Faculty of dental medicine, Medical \\ University - Sofia, Bulgaria.
}

\begin{abstract}
Introduction: The expanded indications for the using a dental operating microscope (DOM) in pediatric dentistry with minimal intervention include an application for the microscope in discovering specific, clinical criteria for the differential diagnosing of pulpitis, requiring different medical approaches.

Aim: To study the application of magnifying technology with a DOM in the diagnosis of asymptomatic closed pulpitis in primary molars

Material and methods: Subject of the study were 40 primary molars (19 first and 21-second molars) of children (20 girls and 20 boys) at the ages of 4-7, with cavitated carious lesions in the dentine. The visual clinical diagnosis was carried out by simple visual inspection and also with the use of magnifying technology DOM (Semorr DOM3000E) at a magnification factor of 8, 16 and 23.3 in accordance with a standardized methodology. An assessment of the carious dentine, with and without DOM, was made. The visual-tactile method of Bjorndal was used.

Results: The use of DOM in the course of diagnosis contributes to a more detailed and precise assessment of the size of the carious lesions, which is an important diagnostic criterion. The use of magnifying technology is an excellent tool for making a precise differential diagnosis between deep dentine caries and asymptomatic pulpitis. When using a DOM, there is a greater diversity of the colours and nuances of the carious dentine, with lighter shades being predominant, which is an indicator of predominantly faster development of the carious lesion.
\end{abstract}

Keywords: dental operating microscope, reversible pulpitis, minimally invasive dentistry,

In recent years, new high-tech diagnostic tools and methods have gained ground in the sphere of dental medicine, which gives the opportunity for applying the principles of minimal intervention treatment $[1,2]$. In this regard, the use of magnifying tools has revolutionized dental practice and ushered in advancement from the conventional methods of macrodental medicine to the high-precision microdental medicine - the minimally invasive approach, through the use of optical magnifying tools. The micro- assisted, precise dental medicine has proven clinical successes and has been adopted as the new standard in dental treatment. This key piece of technology marks a change in the present and future tendencies of dental diagnostics, including those of pediatric dental medicine $[3,4,5]$.

The expanded indications for the application of the dental operating microscope (DOM) in pediatric dentistry with minimal intervention include an application for the microscope in discovering specific, clinical criteria for the differential diagnosing of pulpitis, requiring different medical approaches. DOM makes it possible to examine and photodocument the anatomical characteristics of primary molars in a clinical environment, and it also enables a more precise diagnosing of asymptomatic pulpitis in primary teeth $[1,3,4]$.

In differential diagnostics between deep dentin caries and reversible pulpitis, dental practitioners rely primarily on visual clinical criteria. According to some authors, changes in the pulp can be observed as soon as the deep caries stage, characteristic of reversible pulpitis, and the lack of clinical symptoms is no indication of a lack of pulp pathology. In publications by said authors, they support the thesis that a deep carious lesion could be associated with an asymptomatic inflammation of the pulp $[5,6,7,8$, 9]. Its size and positioning in relation to the affected, adjacent tubercles are the only clinical criteria for differentiating between asymptomatic pulpitis from a deep dentinal caries.

Such a diagnostic method requires the best possible visibility and magnification for identifying the specific visual clinical criteria of the carious lesion when it is suspected that it might be an asymptomatic pulpitis lesion.

\section{Aim}

To study the application of magnifying technology with a dental operating microscope (DOM) in the diagnosis of asymptomatic closed pulpitis in primary molars.

\section{Tasks:}

1. To provide a clinical diagnosis of asymptomatic closed pulpitis in primary molars with and without the use of a DOM

2. To provide a description of carious dentine in asymptomatic pulpitis in primary molars with and without the use of a DOM. 


\section{MATERIALS}

The subject of the study was cavitated carious dentine lesions of 40 primary molars (19 first and 21-second molars) in 40 healthy children between the ages of four and seven. Children were included in the study only after a detailed explanation to their parents regarding the aims of the study and the treatment methods and after receiving their informed written consent. We had received ethical approval from KENIMUS - Ethical commission of Medical University of Sofia - 24/07.12.2018. The visual clinical diagnosis was carried out by simple visual inspection and also with the use of magnifying technology DOM (Semorr DOM3000E) at a magnification factor of 8, 16 and 23.3 in accordance with a standardized methodology, described below, and precise photo-documentation. The data regarding each tooth were put down in a medical card that was developed specifically for the purposes of the study.

\section{METHODS}

- Clinical methods for the diagnosis of asymptomatic closed pulpitis

The primary molars had large cavitated dentine cari- ous lesions, diagnosed after a conventional clinical examination. In order for them to be included in the study, they had to comply with the following clinical criteria:

- lack of spontaneous pain and night pain;

- a large dentine carious lesion - occlusal or approximal;

- lack of reddening or pain during palpation of the adjacent gingiva;

- lack of pulp communication;

- lack of pain during percussion;

The size, localization, consistency and colour of the carious dentine were determined for each of the carious lesions. At the second stage of the study, all of the carious lesions were diagnosed with and without DOM (8x, 16x, and $23.3 \mathrm{x}$ ), according to the specialized criteria for asymptomatic pulpitis.

- Diagnostic criteria for assessing the size of the carious lesions

Assessment of the size of the carious lesions, in relation to their localization, was carried out according to the criteria described in table 1.

Table 1. Clinical visual criteria for assessing the size of the carious lesions, in relation to their localization

\begin{tabular}{|l|l|l|}
\hline & \multicolumn{1}{|c|}{$\begin{array}{c}\text { Carious lesion D3b - code 1 } \\
\text { pulpitis- code 2 }\end{array}$} \\
\hline $\begin{array}{l}\text { Occlusal } \\
\text { localization }\end{array}$ & $\begin{array}{l}\text { - the contours of the lesion do not reach the mid- } \\
\text { dle of the distance between the deepest point } \\
\text { of the fissure and the top of the cusp; } \\
\text { - lack of cusp destruction due to caries; }\end{array}$ & $\begin{array}{l}\text { - the contours of the lesion reach the middle of } \\
\text { the distance between the deepest point of the fis- } \\
\text { sure and the top of the cusp; } \\
\text { - presence of a cusp destroyed by caries; }\end{array}$ \\
\hline $\begin{array}{l}\text { Approximal } \\
\text { localization }\end{array}$ & $\begin{array}{l}\text { - up to } 1 / 3 \text { of the approximal surface is affected; } \\
\text { - the adjacent cusp remains unaffected; }\end{array}$ & $\begin{array}{l}\text { - up to or more than 2/3 of the approximal sur- } \\
\text { face is affected; } \\
\text { - cusp is affected or destroyed due to caries; }\end{array}$ \\
\hline
\end{tabular}

- Visual-tactile criteria for dentine assessment

The visual-tactile characteristics of the carious dentine were registered through a simple visual inspection and with DOM, with three degrees of magnification $-8 \mathrm{x}, 16 \mathrm{x}$ and 23.3x. The visual-tactile method of Bjorndal was used [10].

The SPSS (version 19, SPSS Inc., USA) was used for the statistical processing of the results. A $95 \%$ confidence interval $(\mathrm{p}<0.05)$ was chosen as a level of significance at which the null hypothesis is rejected.

\section{RESULTS}

1. Visual clinical diagnosis with and without the use of DOM of the primary molars studied

The size of the carious lesions was determined clinically with and without the use of DOM. The results are presented in table 2 and table 3.

Table 2. Size of the carious lesions in relation to their localization - assessment without DOM

\begin{tabular}{|c|c|c|c|c|c|}
\hline & \multicolumn{2}{|c|}{ occlusal } & \multicolumn{2}{|c|}{ approximal } & \\
\hline & $\mathrm{N}$ & $\% \pm \mathrm{sp}$ & $\mathrm{N}$ & $\% \pm \mathrm{sp}$ & \\
\hline Code 1 & 4 & $25 \pm 10.83$ & 4 & $16.7 \pm 7.61$ & $\mathrm{~T}=0.63 \quad \mathrm{p}>0.05$ \\
\hline Code 2 & 12 & $75 \pm 10.83$ & 20 & $83.3 \pm 7.61$ & $\mathrm{~T}=0.63 \quad \mathrm{p}>0.05$ \\
\hline \multirow[t]{2}{*}{ total } & 16 & $100 \%$ & 24 & $100 \%$ & \\
\hline & & $17 \quad \mathrm{p}<0.05$ & & $\begin{array}{ll}0 & \mathrm{p}<0.05\end{array}$ & \\
\hline
\end{tabular}

Code 1 - visual clinical data of carious lesion D3b

Code 2 - visual clinical data of carious lesion D4 (asymptomatic closed pulpitis) 
In the clinical assessment, without the use of magnification tools, $75 \%$ of the occlusal and $83.3 \%$ of the approximal lesions show clinical indications of asymptomatic pulpitis $(\mathrm{p}<0.05$, table 2$)$. When DOM was used with an $8 x$ degree of magnification, all 40 carious lesions showed visual clinical indications of asymptomatic pulpitis. The assessment was carried out according to the criteria described in the Methods.

Table 3 shows the clinical diagnoses of the carious lesions, made through a simple visual inspection and with DOM.

Table 3. Comparison of the clinical diagnoses, made with and without a microscope

\begin{tabular}{|l|c|c|c|c|c|c|}
\hline \multirow{2}{*}{} & \multicolumn{2}{|c|}{ Code 1 } & \multicolumn{2}{c|}{ Code 2 } & \multicolumn{2}{c|}{ total } \\
\cline { 2 - 7 } & $\mathrm{N}$ & $\% \pm \mathrm{sp}$ & $\mathrm{N}$ & $\% \pm \mathrm{sp}$ & $\mathrm{N}$ & $100 \%$ \\
\hline Without DOM & 8 & $20.0 \pm 6.32$ & 32 & $80.0 \pm 6.32$ & 40 & $100 \%$ \\
\hline DOM - 8x magnification & 0 & $0 \pm 0$ & 40 & $100 \pm 0$ & 40 & $100 \%$ \\
\hline & \multicolumn{7}{|c|}{$\mathrm{T}=3.16 \mathrm{p}<0.05$} & \\
\hline
\end{tabular}

Code 1 - visual clinical data of carious lesion D3b

Code 2 - visual clinical data of carious lesion D4 (asymptomatic closed pulpitis)

The data shows that there is a discrepancy in $20 \%$ of the diagnosed carious lesions between the diagnoses made with and without DOM $(\mathrm{p}<0.05$, table 3$)$. The results demonstrate the greater precision and accuracy in the differential diagnosis between the deep carious lesion and asymptomatic pulpitis, when using magnifying technology.

Fig. 1. A photo - maxillary second primary molar with clinical indications of asymptomatic closed pulpitis. An undermining and a change in the enamel's transparency are present, as well as underlying carious dentine, with the lesion surpassing the middle between the lowest point of the fissure and the top of the cusp.

Without microscope

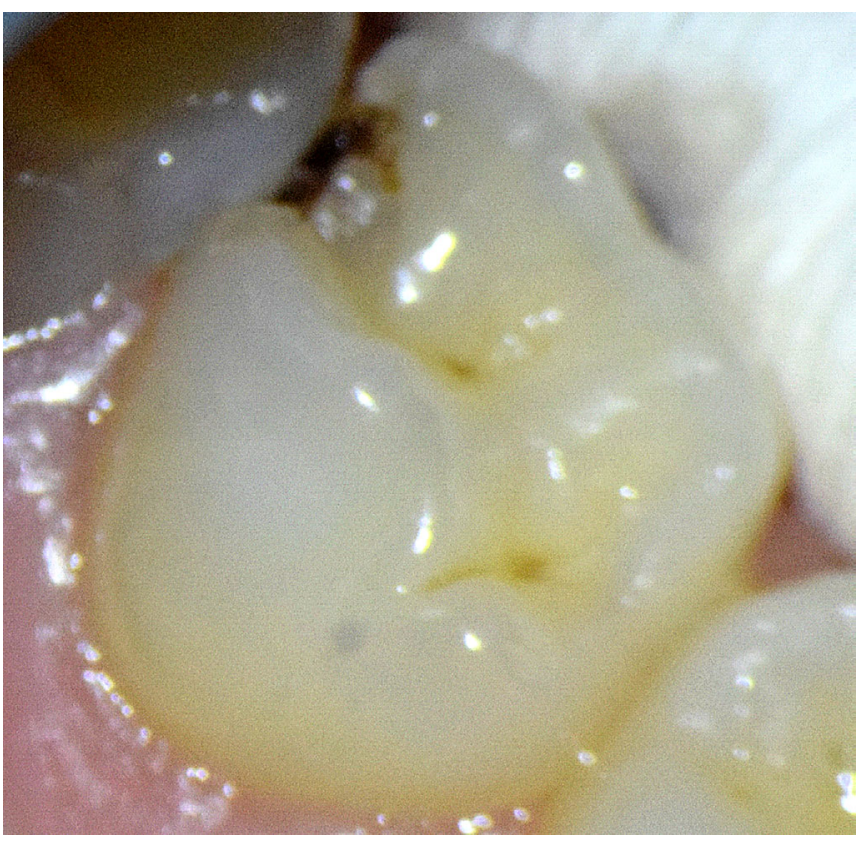

With DOM 8x magnification

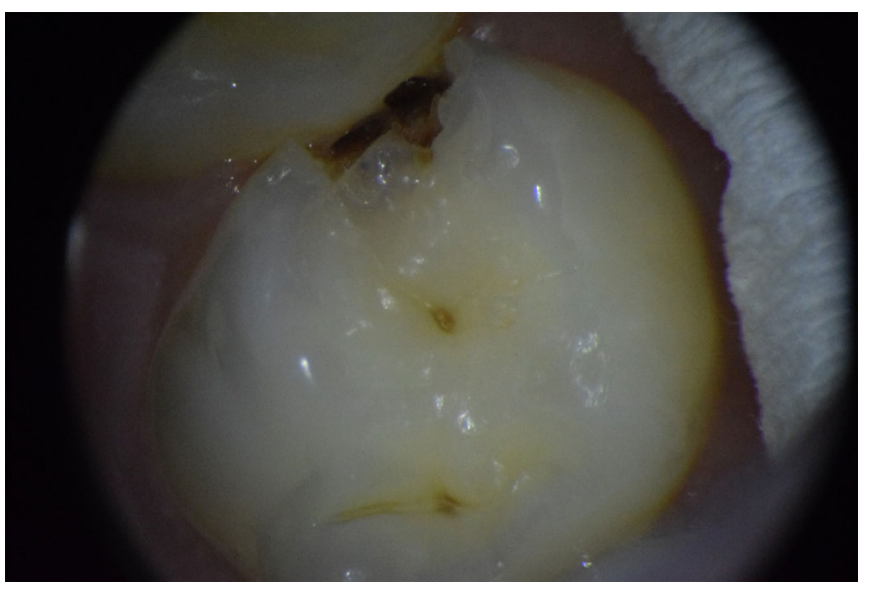
out DOM

2. Description of the carious dentin with and with-

- Consistency of the carious dentine

The consistency of the carious dentine of the asymptomatic pulpitis, registered in this study, was assessed through the visual-tactile method, without the help of magnifying technology. The results are presented in Table 4. 
Table 4. Consistency of the carious dentine according to the lesion's localization

\begin{tabular}{|c|c|c|c|c|c|c|c|}
\hline \multirow{2}{*}{$\begin{array}{l}\text { consistency } \\
\text { localization }\end{array}$} & \multicolumn{2}{|r|}{ Very soft } & \multicolumn{2}{|r|}{ Soft } & \multicolumn{2}{|c|}{ total } & \\
\hline & $\mathrm{N}$ & $\% \pm \mathrm{sp}$ & $\mathrm{N}$ & $\% \pm \mathrm{sp}$ & $\mathrm{N}$ & $100 \%$ & \\
\hline Occlusal & 12 & $75.0 \pm 10.83$ & 4 & $25.0 \pm 10.83$ & 16 & $100 \%$ & $\mathrm{~T}=3.27 \mathrm{p}<0.05$ \\
\hline \multirow[t]{2}{*}{ Approximal } & 20 & $83.3 \pm 7.61$ & 4 & $16.7 \pm 7.61$ & 24 & $100 \%$ & $\mathrm{~T}=6.20 \mathrm{p}<0.05$ \\
\hline & & $\mathrm{T}=0.63 \quad \mathrm{p}>0.05$ & & $\mathrm{~T}=0.63 \mathrm{p}>0.05$ & & & \\
\hline
\end{tabular}

Pearson Chi-Square $=0.417 \quad \mathrm{Sig}=0.519$

The consistency of the carious dentine is predominantly very soft in the lesions, suspected of being pulpitis with occlusal and approximal localization $(\mathrm{p}<0.05$, table 4$)$.

- Colour of the carious dentine

A comparison of the colour of the carious dentine was made, which was clinically registered both with and without the use of a DOM, with 8x, 16x and 23.3x degrees of magnification. The results are presented in Table 5.

Table 5. Dentine colour assessment with and without the use of DOM with $8 x, 16 x$ and 23.3x degrees of magnification

\begin{tabular}{|l|c|c|c|c|c|c|c|c|}
\hline \multirow{2}{*}{ Colour } & \multicolumn{2}{|c|}{ Dark-brown (1) } & \multicolumn{2}{|c|}{ Light-brown (2) } & \multicolumn{2}{|c|}{ Dark-yellow (3) } & Lesions total \\
\cline { 2 - 9 } & $\mathrm{N}$ & $\% \pm \mathrm{sp}$ & $\mathrm{N}$ & $\% \pm \mathrm{sp}$ & $\mathrm{N}$ & $\% \pm \mathrm{sp}$ & $\mathrm{N}$ & $100 \%$ \\
\hline No microscope & 17 & $42.5 \pm 7.82$ & 23 & $57.5 \pm 7.82$ & 0 & $0 \pm 0$ & 40 & $100 \%$ \\
\hline Magnification - 8x & 14 & $35.0 \pm 7.54$ & 16 & $40.0 \pm 7.75$ & 10 & $25.0 \pm 6.85$ & 40 & $100 \%$ \\
\hline Magnification - 16x & 14 & $35.0 \pm 7.54$ & 16 & $40.0 \pm 7.75$ & 10 & $25.0 \pm 6.85$ & 40 & $100 \%$ \\
\hline Magnification - 23.3x & 14 & $35.0 \pm 7.54$ & 16 & $40.0 \pm 7.75$ & 10 & $25.0 \pm 6.85$ & 40 & $100 \%$ \\
\hline & \multicolumn{2}{|c|}{$\mathrm{T}=0.690 \quad \mathrm{p}>0.05$} & $\mathrm{~T}_{1,2}=1.590 \quad \mathrm{p}>0.05$ & & \multicolumn{5}{l}{} \\
\hline
\end{tabular}

Pearson Chi Square $=18.919 \mathrm{Sig}=0.000$

Lighter shades of the carious dentine (dark-yellow) can be observed during the clinical assessment with DOM in 1/4 of the cases. When examined without a microscope, those cases were predominantly assessed to be with lightbrown carious dentine (table 5).The results show that there are no observable differences in the registered colour of the carious dentine between the various degrees of magnification of the microscope ( $p>0.05$, table 5$)$. This conclusion indicates that observation with an 8x DOM magnification is perfectly sufficient to fully realize its diagnostic potential in regard to a more precise diagnosis of the extent of the progression of the carious lesion, its proximity to the pulp and its involvement in the inflammatory process of the primary molars.

The colour of the carious dentine, as a diagnostic criterion, is an indicator for the speed of development of the carious destruction, which reflects on the defence reaction of the pulp-dentine complex. The possibility for a more accurate assessment of the nuance of the carious dentine when using a DOM assist in the making of a more accurate diagnosis.

\section{DISCUSSION}

Determining the degree of involvement of the pulp in the inflammatory process is a key, but also a difficult stage in the process of diagnosing pulpitis in primary mo- lars $[11,12]$. The diagnosis requires a targeted case history, a thorough clinical examination, paraclinical tests and more. The size and localization of the carious lesion are of some the important clinical criteria during the course of the differential diagnosis between deep dentine caries and asymptomatic pulpitis. In early childhood, the opportunity for a precise and accurate clinical assessment is crucial, as the case history, subjective information and thermal testing during a clinical examination are not always an available and reliable source of information [11, 12].

In the clinical practice, there exist various methods for diagnosing the changes, accompanying the progression of the carious lesion, that employ visible light, fluorescence, $x$-ray images and others. Several studies in the scientific literature show that the use of fluorescence increases the possibility for a correct diagnosis and that it best objectives and describes the condition of the carious dentine in the presence of cavitated lesions [13, 14, 15]. According to other authors, fluorescence aids in the process of making a clinical decision during the course of diagnosing, but gives no significant advantage over a visual examination or x-ray images $[16,17]$. Research from our team and other authors shows that fluorescent control during the course of excavation makes it possible to carry out a precise and minimally invasive selective excavation during the course of treatment of deep dentine lesions of perma- 
nent teeth and of biological treatment of asymptomatic pulpitis of primary molars $[19,20]$.

This study established that in $20 \%$ of the diagnosed carious lesion, there is a discrepancy between the diagnosis with and without DOM. The results showed that the use of DOM during clinical examinations gives more accurate information regarding the size and extent of the lesion, as well as the possibility for more precisely determining its outer borders $(\mathrm{p}<0.05$, table 3$)$. When examining with a DOM, diagnosis is more precise, and all examined lesions in the dentine showed clinical characteristics of asymptomatic closed pulpitis, in relation to the size, location and the affecting of the adjacent cusp. The use of magnifying technology gives the opportunity for detailed visualization of micro-cavitations, changes in the enamel's transparency around the borders of the lesion and fractured enamel edges, which could be invisible to the naked eye. Having a clear and precise idea of the scope of the lesion is an important indicator regarding the degree of progression of the carious lesion. This fact makes it possible to assess the degree of involvement of the pulp in the inflammatory process.

The results of this study are basic enough to assume that the use of DOM at an $8 \mathrm{x}$ degree of magnification is sufficient and gives an opportunity for greater accuracy and precision, and is complementary to the objective assessment in determining the differential diagnosis between deep dentine caries and closed asymptomatic pulpitis.

In relation to the colour of the carious dentine, the results show that predominant are the lighter shades, which is an indication of a faster progression of the carious process and of involvement of the dental pulp (tables 5). The rapid advancement of the inflammatory process in primary teeth is further facilitated by their physiological and morphological characteristics - wider dental tubules, thinner enamel and dentine layers, lower degree of mineralization, wider and more exposed pulp chamber, which leads to the rapid involvement of the pulp [21]. Assessment of the changes in the colour of the dentine is an important diagnostic indicator when applying the minimally invasive and precise approach during biological treatment of asymptomatic pulpitis in primary teeth [4].

The minimally invasive approach, related to the treatment of reversible pulpitis, requires a precise and reliable diagnosis, which is very crucial in regard to the choice of the appropriate treatment method and its successful heal- ing process. The availability of objective clinical criteria is of great importance for pediatric patients, especially when the process affects the primary teeth, where there is no adequate and plausible objective information to rely on. Precise diagnostics in cases of asymptomatic closed pulpitis will make it possible to successfully apply indirect pulp cupping and to preserve the vitality of the tooth, which in turn creates the conditions for a successful treatment and the proper progression of the physiological resorption.

There are studies in the scientific literature on the importance of using DOM and magnifying technology in the diagnosis of initial fissure caries in permanent teeth, but there are no studies, regarding their role in the diagnosis of deep carious lesions and asymptomatic pulpitis in primary teeth $[22,23]$. The results of this study show that using a DOM provides an advantage and precision both in the diagnosis of and the choice of a treatment method for asymptomatic pulpitis in primary molars.

\section{CONCLUSIONS:}

1. The use of a DOM in the course of diagnosis contributes to a more detailed and precise assessment of the size of the carious lesions, which is an important diagnostic criterion;

2. The use of magnifying technology is an excellent tool for making a precise differential diagnosis between deep dentine caries and asymptomatic closed pulpitis;

3. When using a DOM, there is a greater diversity of the colours and nuances of the carious dentine, with lighter shades being predominant, which is an indicator of predominantly faster development of the carious lesion;

4. The more accurate and precise colour description of the dentine in diagnosis with a DOM gives an opportunity for greater precision in determining the speed of the carious process;

5. During biological treatment of asymptomatic closed pulpitis of primary teeth, the use of magnifying technology - DOM gives the opportunity for a more precise diagnosis and choice of treatment method, which is a condition for a successful outcome.

\section{Acknowledgement}

This work was supported by the Council of Medical Science at Medical University of Sofia, Bulgaria under Infrastructure Project with Contract No. 207/12.12.2018.

\section{REFERENCES:}

1. Murgel C. Microdentistry: Concepts, Methods, And Clinical Incorporation. Int J MicroDent. 2010; 2(1):5663. [Internet]

2. Peneva M, (Editor). [Clinic of pediatric dentistry]. [in Bulgarian]. Bedemot, Sofia, 2018:143-318.

3. Fanibunda U, Meshram G, Warhadpande M. Evolutionary Perspectives On The Dental Operating
Microscope: A Macro Revolution At The Micro Level. Int J Micro Dent. 2010; 2(1):15-19.

4. Ricketts D, Lamont T, Innes NP, Kidd E, Clarkson JE. Operative caries management in adults and children. Cochrane Database Syst Rev. 2013 Mar;28(3):CD003808. [PubMed] [Crossref] .

5. Schwendicke F, Paris S, Tu Y. Ef- fects of using different criteria and methods for caries removal: a systemic review and network meta-analysis. $J$ Dent. 2015 Jan; 43(1):1-15. [PubMed] [Crossref]

6. Schwendicke F, Jäger AM, Paris S, Hsu LY, Tu YK. Treating pit-and-fissure caries: a systematic review and network meta-analysis. J Dent Res. 2015 Apr;94(4):522-533. [PubMed] 
[Crossref]

7. Schwendicke F, Frencken JE, Bjordnal L, Maltz M, Manton DJ, Ricketts D, et al. Managing caries removal: consensus recommendations on carious tissue removal. Adv Dent Res. $2016 \quad$ May;28(2):58-67. [PubMed] [Crossref]

8. Schwendicke F, Frenken J, Innes N. Caries Excavation Evolution of Treating Cavitated Carious Lesions. Karger, Basel. 2018; vol.27. pp.186. [Crossref]

9. Schwendicke F. Removing Carious Tissue: Why and How? Monogr Oral Sci. 2018 May;27:56-67. [PubMed] [Crossref]

9. Innes NP, Frencken JE, Bjorndal L, Maltz M, Manton DJ, Ricketts D, et al. Managing caries lesion: consensus recommendations on terminology. Adv Dent Res. 2016 May;28(2):49-57. [PubMed]

10. Bjørndal L, Larsen T, Thylstrup A. A Clinical and Microbiological Study of Deep Carious Lesions During Stepwise Excavation Using Long Treatment Intervals. Caries Res. 1997; 31(6):411-7. [PubMed] [Crossref]

11. Smail-Faugeron V, Glenny AM, Courson F, Durieux P, Muller-Bolla M, Fron Chabouis H. Pulp treatment for extensive decay in primary teeth. Cochrane Database of Systematic Reviews. 2018; 5:CD003220. [Crossref]

12. Santamaria RM, Innes NP, Machiulskiene V, Evans DJ, Splieth $\mathrm{CH}$. Caries management strategies for primary molars: 1-yr randomized control trial results. J Dent Res. 2014 Nov; 93(11):1062-1069. [ [PubMed] [Crossref]

13. Iwami Y, Shimizu A, Narimatsu M, Hayashi M, Takeshige F, Ebisu S. Relationship between bacterial infection and evaluation using a laser fluorescence device, DIAGNOdent. Eur J Oral Sci. 2004 Oct;112(5):419-423. [PubMed] [Crossref]

14. Lai G, Zhu L, Xu X, Kunzelmann KH. An in vitro comparison of fluorescence-aided caries excavation and conventional excavation by microhardness testing. Clin Oral Investig. 2014 May;18(2):599-605. [PubMed] [Crossref]

15. Lennon A, Attin T, Martens S, Buchalla W. Fluorescence-aided caries excavation (face) caries detector and conventional caries excavation in primary teeth. Pediatr Dent. 2009 JulAug; 31(4):316-319. [PubMed]

16. Rechmann P, Charland D, Rechmann BMT, Featherstone JDB. Performance of Laser Fluorescence Devices and Visual Examination for the Detection of Occlusal Caries in Permanent Molars. J Biomed Opt. 2012 Mar;17(3):036006. [PubMed] [Crossref]

17. Rechmann P, Liou SW, Rechmann BMT, Featherstone JDB. Performance of a light fluorescence device for the detection of microbial plaque and gingival inflammation. Clin Oral Investig. 2016 Jan;20(1):

\section{1-9. [ $\underline{\text { PubMed] [Crossref] }}$}

18. Mendes FM, Novaes TF, Matos R, Bittar DG, Piovesan C, Gimenez T, et al. Radiographic and Laser Fluorescence Methods Have No Benefits for Detecting Caries in Primary Teeth. Caries Res. 2012; 46(6):536-43. [PubMed] [Crossref]

19. Mitova N, Rashkova M, Uzunov T, Kosturkov D, Petrunov V. [Controlled excavation for cavitated dentinal caries with visual-tactile method and fluorescence with Proface W\&H]. Problems of dental medicine; 2014; 40(1):13-21. In Bulgarian.

20. Mitova N. [Minimally invasive approach to dentine caries of permanent teeth in children] [dissertation]. Sofia (Bulgaria): MU-Sofia, 2016. 275 p. [in Bulgarian].

21. Schwendicke F, Dorfer CE, Paris S. Incomplete caries removal: a systemic review and meta-analysis. $J$ Dent Res. 2013 April; 92(4):306-314. [PubMed] [Crossref].

22. Zafersoy-Akarslan Z, Erten H, Uzun O, Semiz M. Reproducibility and agreement of clinical diagnosis of occlusal caries using unaided visual examination and operating microscope. J Can Dent Assoc. 2009 Jul; 75(6):455. [PubMed].

23. Sisodia N, Manjunath MK. Impact of Low Level Magnification on Incipient Occlusal Caries Diagnosis and Treatment Decision Making. $J$ Clin Diagn Res. 2014 Aug;8(8):ZC32ZC35. [PubMed] [Crossref].

Please cite this article as: Rashkova M, Gateva N, Mitova N, Lazarova Z, Tankova H. Using a dental operating microscope in the diagnostics of asymptomatic pulpitis in primary teeth. $J$ of IMAB. 2020 Jan-Mar;26(1):2975-2980.

DOI: https://doi.org/10.5272/jimab.2020261.2975

Received: 28/10/2019; Published online: 13/03/2020

\author{
Address for correspondence: \\ Nadezhda Georgieva Mitova \\ Department of Pediatric Dentistry, Faculty of dental medicine, Medical \\ University - Sofia, \\ 1, Georgi Sofiisky str., Sofia, Bulgaria. \\ E-mail: nadia_bm@abv.bg
}

